\title{
AN ATTEMPT TO MODIFY THE AGGLUTINABILITY OF THE TYPHOID BACILLUS BY SELEC'TIVE ISOLATION OF INDIVIDUAL BACILLI.*
}

\author{
V. H. M OON. \\ (From the Uritersity of Kansas.)
}

All observers have noted in performing agglutination experiments, even with highly agglutinative serum in low dilutions, that some individual bacilli may resist agglutination and remain floating free in the serum. The object of this series of experiments was to determine whether this failure to clump is due to some peculiar property of the bacillus which can be transmitted to its descendants.

\section{METHOD,}

To isolate individual bacilli selectively seemed necessary as a means for this investigation. The most precise method for accomplishing this selective isolation is the technic designed and developed by Dr. M. A. Barber of the University of Kansas. ${ }^{x}$ By using a microscopic capillary pipette supported in a mechanical holder provided with motion in three directions, one is able after considerable practice to isolate individual micro-organisms from a hanging drop. This drop is supported by a cover-glass over a moist chamber which is held and moved about under the microscope by the ordinary mechanical stage. The details of the method are fully described in the articles above referred to.

The medium used was meat broth carefully made according to the American Public Health Association standard, reaction 0. 7 per cent acid to phenolphthalein. To begin with, an absolutely pure strain of $B$. typhosus was obtained by isolating an individual bacillus from a culture obtained from the laboratories of Johns Hopkins University. The resulting colony was transferred to broth and several agar slants were inoculated from this and labeled "Stock." A drop of the broth culture was placed on a sterile

* Received for publication April I, IgI I.

Iour. Infect. Dis., 1908, 5, D. 380; Kansas University Science Bulletin, 1907, p. 3. 
cover-glass, and agglutination performed by adding an equal part of serum diluted $I: I 6$. The serum used throughout this experiment was human: serum from the same individual drawn under aseptic conditions and proved sterile by broth culture. It agglutinated typhoid bacilli at $\mathrm{r}: 96$ dilution. As soon as clumping began a single definite clump was selected and isolated by means of the capillary pipette. The experiment was then allowed to stand one hour and 45 minutes at room temperature about $26^{\circ} \mathrm{C}$. Then several individual bacilli which had resisted clumping were isolated and planted separately in small hanging drops. Chemically clean glass tubing was used for making all pipettes. For making each transfer of cultures, broth, or serum, and for each operation of isolation a new, freshly drawn pipette was used. The cover-glass was then transferred to a vaselinesealed hollow-ground slide of large size and incubated 24 hours at $35^{\circ} \mathrm{C}$. From this time on a double series of isolations and cultures was made. In the one series the first clumps to form were isolated, and in the other the individuals which resisted agglutination were selected and allowed to form colonies. For convenience we will refer to these as $+\mathrm{S}$ and $-\mathrm{S}$ respectively, the $+\mathrm{S}$ referring to that series selected on the basis of ready clumping and the $-S$ to the series developed by selecting the resistant individuals. A number following the $S$ indicates the number of selections made in that series.

After making five selections and cultures of the $+\mathrm{S}$ and four of the $-\mathrm{S}$ a preliminary comparative agglutination test was made with results as shown in the following table.

\begin{tabular}{c|c|c|c|c|c|c|c}
\hline Dilution & $1 / 16$ & $1 / 24$ & $\mathrm{I} / 32$ & $\mathrm{~T} / 48$ & $\mathrm{r} / 64$ & $\mathrm{I} / 96$ & Control \\
\hline$+\mathrm{S}_{5} \ldots \ldots \ldots \ldots \ldots \ldots$ & + & + & + & + & \pm & $\stackrel{?}{-}$ & - \\
\hline
\end{tabular}

In making this test 24-hour agar cultures were used and the dilutions were examined microscopically. The writer in this case knew the identity of the cultures, but in all subsequent tests the cultures were marked in cipher by a second person and their identity revealed only after all observations had been made and recorded. One element of the personal equation was thus elimi- 
nated. The following table shows the result of a test in which the original stock was compared with $+\mathrm{S}_{9}$ and $-\mathrm{S}_{8}$.

\begin{tabular}{|c|c|c|c|c|c|c|c|c|}
\hline Dilution & $1 / 32$ & $x / 48$ & $I / 64$ & $1 / 06$ & $\mathrm{I} / \mathrm{r} 28$ & $I / 19^{2}$ & $1 / 250$ & Control \\
\hline $\begin{array}{l}{ }_{+}^{+} S_{9} \\
S_{S} \\
\text { Stock. }\end{array}$ & + & + & $\begin{array}{l}+ \\
? \\
+\end{array}$ & $\frac{ \pm}{t}$ & \pm & \pm & $\bar{z}$ & $\bar{z}$ \\
\hline
\end{tabular}

These results were verified by a second observer before the identity of the cultures was revealed. The test shows a marked increase in the agglutinability of the + series and a corresponding decrease in the agglutinability of the - series.

Following this test the routine of performing agglutinations and selections was continued until 24 selections in the $+S$ and 13 in the $-S$ had been made. The average time of making the + selection was 20 minutes, while the - series were exposed to the action of the serum for two hours before the selections were made. Frequent transfers were made to clean freshly sterilized coverglasses.

The following test was made with I8-hour agar cultures using rabbit serum which agglutinated at about $1: 600$. In this test the macroscopic method was used and the observations were made after three hours at room temperature.

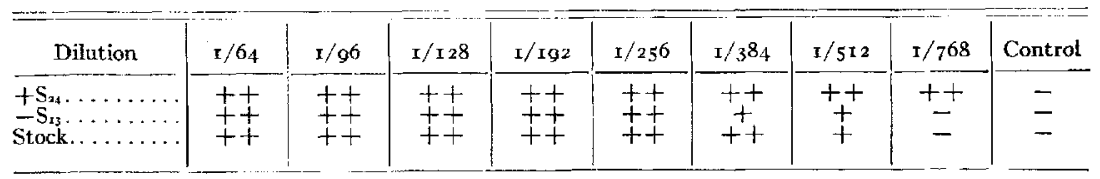

++ means agglutination visible to naked eye.

+ means agglutination visible with hand lens.

Following this test the cultures were kept at room temperature and transferred to fresh media three times in 18 days. Then a final test was made macroscopically, using both rabbit serum and the same human serum which was used in developing the two series. The cultures were marked in cipher as before.

RABBIT SERUM.

\begin{tabular}{|c|c|c|c|c|c|c|c|c|c|}
\hline Dilution & $1 / 102$ & $x / 250$ & $I / 384$ & $I / 500$ & $1 / 768$ & $I / 1000$ & $I / 1500$ & $1 / 2000$ & Control \\
\hline $\begin{array}{l}+S_{24} \ldots \ldots \\
-S_{x_{3}} \ldots \ldots \\
\text { Stock } \ldots \ldots\end{array}$ & $\begin{array}{l}t+ \\
t+\end{array}$ & $\begin{array}{l}+t \\
+t \\
++\end{array}$ & $\begin{array}{l}+t \\
+t\end{array}$ & $\begin{array}{l}t+ \\
+t\end{array}$ & $\begin{array}{l}++ \\
++ \\
++\end{array}$ & $\begin{array}{l}+t \\
+t \\
+t\end{array}$ & + & \pm & $\bar{z}$ \\
\hline
\end{tabular}


HUMAN SERUM.

\begin{tabular}{c|c|c|c|c|c|c|c|c}
\hline Dilution & $1 / 16$ & $1 / 24$ & $1 / 32$ & $1 / 48$ & $1 / 64$ & $1 / 96$ & $1 / 128$ & Control \\
\hline$+\mathrm{S}_{24} \ldots \ldots \ldots \ldots$ & ++ & ++ & ++ & ++ & ++ & ++ & + & $=$ \\
\hline $\mathrm{S}_{13} \ldots \ldots \ldots \ldots$ & ++ & ++ & ++ & ++ & ++ & ++ & + & $=$ \\
\hline
\end{tabular}

CONCLUSIONS.

The first two tests showed decided differences in the agglutinability of the two series. However in the final tests no such difference was evident. In the one the $-S_{x_{3}}$ agglutinated more readily than the $+S_{24}$, and in the other test the $-S_{x_{3}}$ agglutinated more readily than the stock. So we must conclude that, whatever differences in agglutinability were developed, they failed to become permanent or even to persist through the number of generations which would take place in an agar medium in $\mathrm{r} 8$ days at $26^{\circ} \mathrm{C}$.

The author wishes to express his indebtedness to Dr. M. A. Barber for his patient instruction and oversight during the progress of the work. 